\title{
Bromodomain factor 1 corresponds to a missing piece of yeast TFIID
}

\author{
Oranart Matangkasombut, ${ }^{1,2}$ Robin M. Buratowski, ${ }^{1}$ Nathan W. Swilling, ${ }^{1}$ and Stephen Buratowski ${ }^{1,3}$ \\ ${ }^{1}$ Department of Biological Chemistry and Molecular Pharmacology, Harvard Medical School, and ${ }^{2}$ Department of Oral \\ Biology, Harvard School of Dental Medicine, Boston, Massachusetts 02115 USA
}

\begin{abstract}
The basal transcription factor TFIID consists of the TATA-binding protein (TBP) and TBP-associated factors (TAFs). Yeast Taf67 is homologous to mammalian $\mathrm{TAF}_{\mathrm{II}} 55$. Using a yeast two-hybrid screen to identify proteins that interact with Taf67, we isolated Bromodomain factor 1 (Bdf1) and its homolog (Bdf2). The Bdf proteins are genetically redundant, as cells are inviable without at least one of the two BDF genes. Both proteins contain two bromodomains, a motif found in several proteins involved in transcription and chromatin modification. The BDF genes interact genetically with TAF67. Furthermore, Bdf1 associates with TFIID and is recruited to a TATA-containing promoter. Deletion of Bdf1 or the Taf67 Bdf-interacting domain leads to defects in gene expression. Interestingly, the higher eukaryotic $\mathrm{TAF}_{\mathrm{II}} \mathbf{2 5 0}$ has an acetyltransferase activity, two bromodomains, and an associated kinase activity. Its yeast homolog, Taf145, has acetyltransferase activity but lacks the bromodomains and kinase. Bdf1, like $\mathrm{TAF}_{\mathrm{II}} 250$, has a kinase activity that maps carboxy-terminal to the bromodomains. The structural and functional similarities suggest that Bdf1 corresponds to the carboxy-terminal region of higher eukaryotic $\mathrm{TAF}_{\mathrm{II}} 250$ and that the interaction between TFIID and Bdf1 is important for proper gene expression.
\end{abstract}

[Key Words: TFIID; bromodomain; transcription; kinase]

Received January 4, 2000; revised version accepted February 25, 2000.

Expression of most genes is controlled at the level of transcription initiation. Transcription by RNA polymerase II (Pol II) requires the assembly of multiple basal transcription factors into a preinitiation complex (PIC) at the core promoter. Promoter recognition is mediated by TFIID. TFIID consists of TATA-binding protein (TBP), which is necessary and sufficient for binding to the TATA element, and 10-12 TBP-associated factors (TAFs). The yeast TAFs are essential for viability, but their role in transcription is still not well understood. Several roles for TAFs have been proposed, including mediation of activated transcription, core promoter selectivity, and cell cycle regulation of transcription (for review, see Verrijzer and Tjian 1996). One recent report suggests that TAFs are required for transcription from chromatin templates (Wu et al. 1999). In vitro experiments suggested that TAFs interact with upstream binding factors to activate transcription (Verrijzer and Tjian 1996). However, other experiments indicate that activated transcription can occur in vitro without TAFs (Burley and Roeder 1996; Oelgeschlager et al. 1998; Wu and Chiang 1998).

Experiments in yeast using temperature-sensitive mutants or targeted depletion of TAFs showed that some

${ }^{3}$ Corresponding author.

E-MAIL steveb@hms.harvard.edu; FAX (617) 738-0516.
TAFs may not be generally required for RNA Pol II transcription (Moqtaderi et al. 1996b; Walker et al. 1996). Mutations in yeast Taf145 or mammalian $\mathrm{TAF}_{\mathrm{II}} 250$, the largest subunit of TFIID, lead to gene-specific defects rather than a general defect in transcription (Walker et al. 1996; Wang et al. 1997). In contrast, several groups reported a more widespread role for the histone-like TAFs in transcription (Apone et al. 1998; Michel et al. 1998; Moqtaderi et al. 1998; Natarajan et al. 1998).

A subset of TAFs, including the histone-like TAFs,

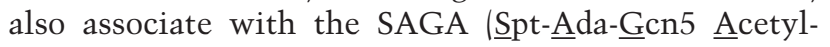
transferase) complex in yeast (Grant et al. 1998a). The corresponding mammalian TAFs or homologs are found in the P/CAF and TFTC acetyltransferase complexes (for review, see Bell and Tora 1999). Therefore, effects of histone-like TAF inactivation result from the simultaneous disruption of both TFIID and SAGA. SAGA-specific components are nonessential (Grant et al. 1998b). Also, deletion of SPT20, which causes a complete loss of SAGA complex (Grant et al. 1997), does not result in a general decrease in poly(A) mRNA level (Michel et al. 1998). Therefore, although it is an important regulator of transcription, SAGA is not generally required for gene expression. Specific disruption of the TFIID complex by a mutation in the TFIID-specific Taf40 protein also causes a widespread loss of RNA Pol II transcription (Komarnitsky et al. 1999). Thus, although every TAF may 
not be required at all promoters, it is likely that TFIID is the species that delivers TBP to Pol II promoters in vivo.

Taf67 is the yeast homolog of human TAF $_{\text {II }} 55$ /Chiang and Roeder 1995; Lavigne et al. 1996; Moqtaderi et al. 1996a). Studies of hTAF 55 suggest that this TAF may be a target of activators (Chiang and Roeder 1995; Lavigne et al. 1999). To study the functions of TAFs and TFIID further, a yeast two-hybrid screen was used to identify proteins that interact with yeast Taf67. Two proteins, Bromodomain factor1 (Bdf1) and its homolog (Bdf2) were isolated.

Bdf1 has been implicated previously in transcription of several genes including snRNAs (Lygerou et al. 1994). However, another genetic screen identified Bdf1 as a chromosomal protein required for sporulation /Chua and Roeder 1995). BDF1 is nonessential, but deletion causes several phenotypes including temperature sensitivity, slow growth, flocculence in liquid culture, and defects in the utilization of some carbon sources. Bdf1 has some sequence similarity to human RING3 and hOrfX proteins, as well as the Drosophila female sterile homeotic protein (Lygerou et al. 1994; Chua and Roeder 1995). Human RING3 was identified as a mitogen-activated nuclear kinase with autophosphorylation activity (Denis and Green 1996). A mouse homolog of RING3 is associated with a mammalian mediator complex (Jiang et al. 1998). The similarity between these proteins and Bdf1 is largely concentrated in two copies of a motif known as the bromodomain. The function of the bromodomain is still unknown, and its importance varies in different proteins. However, there is growing evidence that bromodomains bind to the amino-terminal tails of histones, with a strong preference for the acetylated forms (for review, see Winston and Allis 1999).

Interestingly, the largest higher eukaryotic TAF $\left(\mathrm{TAF}_{\mathrm{II}} 250\right.$ or Ccg1) also contains two bromodomains and an autokinase activity in its carboxy-terminal half. The amino terminal half of $\mathrm{TAF}_{\mathrm{II}} 250$ possesses HAT activity (Dikstein et al. 1996; Mizzen et al. 1996). Taf145, the yeast homolog of $\mathrm{TAF}_{\mathrm{II}} 250$, possesses HAT activity but lacks the two bromodomains and kinase activity. Here, we show that Bdf1 interacts with Taf67 and TFIID genetically and biochemically, and that this interaction plays a role in the regulation of transcription. Furthermore, Bdf1 is also able to autophosphorylate. The structural and functional properties of the protein suggest that Bdf1 corresponds to the carboxy-terminal region of $\mathrm{TAF}_{\mathrm{II}} 250$.

\section{Results}

\section{Bdf1 and Bdf2 interact with Taf67}

To explore the interactions between TFIID subunits, a yeast two-hybrid screen was performed to identify proteins that could interact with a Gal4-binding domainTaf67 fusion. Using a library containing yeast cDNAs fused to the Gal4 activation domain, plasmids were isolated that scored positive in combination with the Taf67 fusion. Of 250,000 clones screened, two were isolated that reproducibly and specifically interacted with the Taf67 fusion. Sequencing of the two clones revealed that one carried the previously described BDF1 gene. The second was identified as YDL070W. Interestingly, a homology search revealed that the YDL070W protein has significant sequence similarity to Bdf1. Because of their physical and functional similarities (see below), YDL070W has been designated Bdf2. Both proteins contain two bromodomain motifs, believed to encode a protein module involved in binding to histone tails.

Deletion mapping of both Bdf1 and Bdf 2 indicated that the bromodomains were not necessary for interaction with Taf67 (Fig. 1). Rather, the conserved region carboxyterminal to the bromodomains was necessary and sufficient for interaction. In the Bdf1 protein, Taf67 interaction mapped between residues 494 and 626. Interestingly, expression of several of the Gal4 activation domain-Bdf1 truncation constructs lacking this region but containing bromodomains led to reduced growth rates even in the presence of wild-type Bdf proteins (data not shown). This result echoes the observation of Chua and Roeder (1995) that a Bdf1 protein fused to lacZ near the carboxyl terminus was lethal. Therefore, partially functional Bdf1 fragments may interfere with the function of the wild-type protein. We also noted that highcopy plasmids containing BDF1 also caused some growth retardation, suggesting a titration of some important limiting factor in cells.

To determine which region of Taf67 interacts with the Bdf proteins, different parts of Taf67 were fused to the Gal4 DNA-binding domain and tested in the two-hybrid system. The amino-terminal 100 amino acids were necessary and sufficient for interaction. This region is rich in basic amino acids and is not conserved in the mammalian homolog $\mathrm{TAF}_{\mathrm{II}} 55$. Another interesting property of this region was noted in the context of the Gal4-binding domain fusions. Unlike many other yeast Tafs that are strong transcriptional activators when fused to a binding domain (Keaveney and Struhl 1998), full-length Taf67 did not activate transcription. However, when the amino-terminal 101 amino acids were deleted, the remaining portion of Taf67 became a potent transcriptional activator. Transcription activation function mapped to residues between 222 and 377, a region conserved over evolution (Fig. 1). In human $\mathrm{TAF}_{\mathrm{II}} 55$, this region interacts directly with $\mathrm{TAF}_{\mathrm{II}} 250$ /Chiang and Roeder 1995). The differential ability of the full-length and truncated Taf 67 proteins to activate transcription was also seen in a BDF1 null background (not shown). It has been argued that activation by Taf and TBP fusions results from recruitment of the entire TFIID complex to the Gal4-binding site. We speculate that the Bdf-interacting region might modulate the interaction between Taf67 and the rest of the TFIID complex.

\section{$B d f 1$ and Bdf2 are redundant}

BDF1 is not essential for viability, but deletion does cause temperature sensitivity, slow growth, flocculence in liquid culture, sensitivity to the DNA-damaging agent 
A Gal4 binding domain - Taf67 plasmids

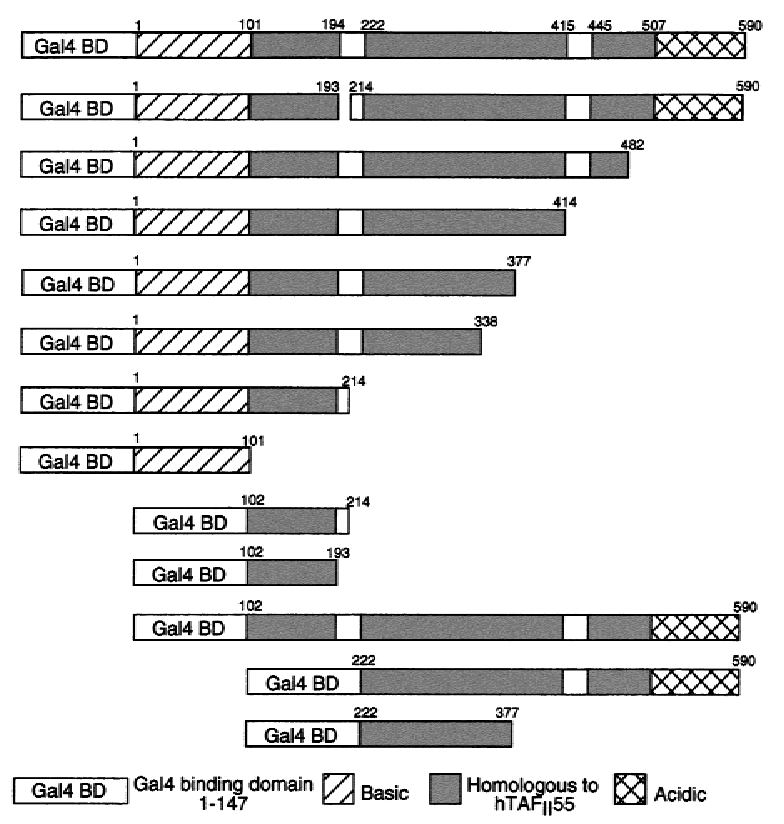

B

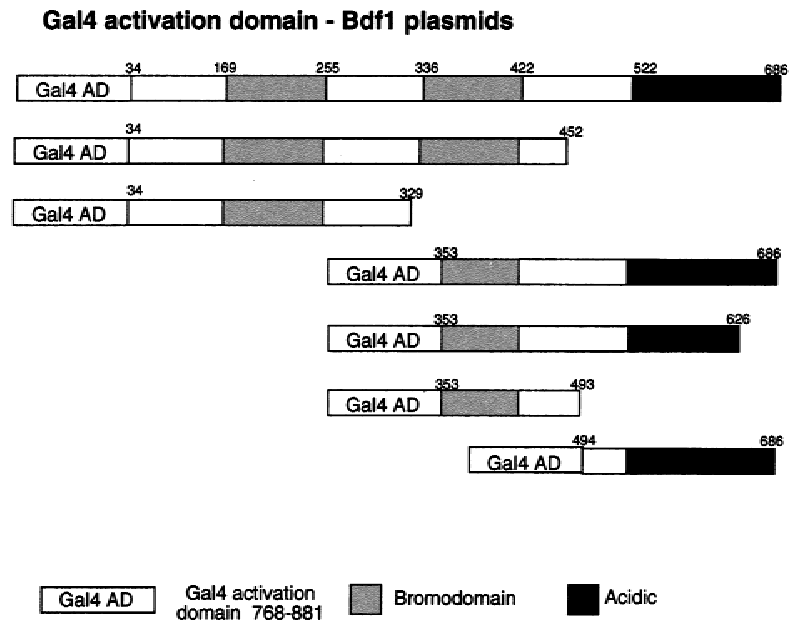

MMS, poor sporulation, and inability to grow on nonfermentable carbon sources (Lygerou et al. 1994; Chua and Roeder 1995). BDF2 has not been characterized previously, so one copy of the gene was replaced with the HIS3 gene in a diploid strain. Sporulation yielded four viable cells and the BDF2 deletion spores grew indistinguishably from wild-type cells. No mutant phenotypes were observed at high or low temperatures, on different carbon sources, in the absence of inositol, or in the presence of caffeine.

Because neither BDF1 nor BDF2 are essential, haploid strains carrying the individual deletions were crossed and sporulated. Of 10 tetrads tested, several had fewer than 4 viable spores and no spores carrying both deletions were recovered. Analysis of the remaining viable spores indicated that the nonviable spores corresponded to double deletions (data not shown). A haploid strain was also constructed containing both deletions and the

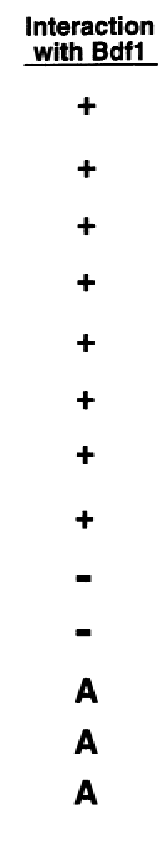

Interaction with Taf67

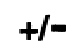

-

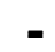

$+$

$+$

-

$+$
Figure 1. Interaction between the amino-terminal basic region of Taf67 and the carboxy-terminal region of Bdf1 in the yeast two-hybrid assay. (A) The Gal4 DNA-binding domain (amino acids 1-147) was fused to the indicated residues of Taf67 and tested for interactions with an activation domain-Bdf1 (residues 353-686) fusion. An interaction was scored positive $(+)$ if the combination of plasmids activated a Gal-HIS3 reporter. A basic region containing amino acids 1-101 of Taf67 was both necessary and sufficient for interaction with Bdf1. Deletion of this region uncovered a latent activation ability of Taf67 amino acids 222-237 (A, activates on its own). (B) The Gal4-activation domain (amino acids 768-881) was fused to the indicated residues of Bdf1 and tested for interactions with the Gal4-binding domain-Taf67 (full length) as described above. A region from amino acids 494-686 was necessary and sufficient for interaction with Taf67. Similar results were obtained for the Bdf2 interaction with Taf67 (data not shown).

BDF1 gene on a URA3 plasmid. This strain was unable to grow in the presence of 5-FOA unless transformed with another plasmid carrying either BDF1 or BDF2. Therefore, $B D F 1$ and $B D F 2$ are genetically redundant, with at least one being necessary for viability. Another argument for functional redundancy of the two Bdf proteins was the finding that a high-copy plasmid carrying $B D F 2$ suppresses the temperature sensitivity of a BDF1 deletion strain (data not shown).

The Bdf-interacting domain is important for Taf67 function

An alignment shows that the Taf67 protein contains two regions not found in its mammalian homolog, a basic region on its amino terminus and an extremely acidic extension at the carboxyl terminus (Moqtaderi et al. 1996a). To determine whether these regions were impor- 


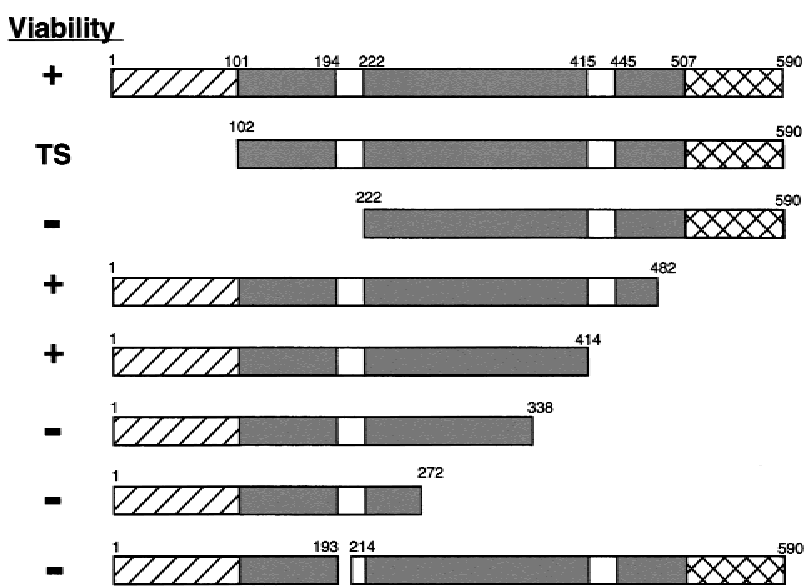

Figure 2. Regions of Taf67 essential for viability. Constructs containing the indicated residues of Taf67 were transformed into YSB424 and tested for complementation of a taf67 deletion by plasmid shuffling. (TS) Viable but temperature sensitive. (Hatched bars) Basic; (shaded bars) homologous to $\mathrm{hTAF}_{\mathrm{II}} 55$; (crosshatched bars) acidic.

tant for Taf67 function, a series of deletion constructs was tested for the ability to complement a complete TAF67 deletion (Fig. 2). It was determined that up to 176 amino acids, including the acidic extension and part of the conserved region, could be deleted from the carboxyl terminus without loss of viability.

The yeast two-hybrid results showed that the aminoterminal region of Taf67 interacts with the Bdf proteins. A deletion lacking 221 amino acids from the amino terminus could not support viability. In contrast, a Taf67 protein lacking the first 101 amino acids, the minimum region necessary for Bdf interaction, allowed growth, but with several mutant phenotypes. taf $67 \Delta N 101$ cells grew very slowly, were temperature sensitive, flocculent in liquid culture, and unable to grow on galactose as a carbon source. These phenotypes are also seen in a $b d f 1 \Delta$ strain, consistent with the hypothesis that the Taf67 amino-terminal region mediates the interaction between the two proteins.

Because the Bdf-interaction domain of Taf67 appeared to be important for its function, we tested whether overexpression of Bdf1 or Bdf2 could suppress the temperature sensitivity of a taf67 6 N101 strain. No suppression was seen; in fact, cells overexpressing Bdf proteins grew slower whether they contained a wild-type or mutant TAF67 allele. Similarly, overexpression of Taf67 did not suppress the temperature sensitivity of the BDF1 deletion. However, taf67 $\Delta$ N101 was synthetically lethal in combination with either $b d f 1 \Delta$ or $b d f 2 \Delta$ (data not shown), providing further genetic evidence for a functional interaction between the proteins.

\section{The Bdf-interacting domain of Taf67 is important} for proper gene expression

To determine whether the interaction between Taf67 and Bdf1 plays a role in transcription, temperature-sen- sitive strains carrying the taf $67 \Delta N 101$ or $b d f 1 \Delta$ allele were analyzed at nonpermissive temperature. The mutants and their isogenic wild-type strains were grown at room temperature. Samples were collected at various times after shifting to $37^{\circ} \mathrm{C}$ and RNA was isolated. Nuclease protection was used to determine the levels of RPS4 and HTA2 transcripts (Fig. 3A) and Northern blotting was performed for ACT1 mRNA (Fig. 3B). The taf67 NN101 strain showed a decrease in all three transcripts after shift to nonpermissive temperature. The ki-

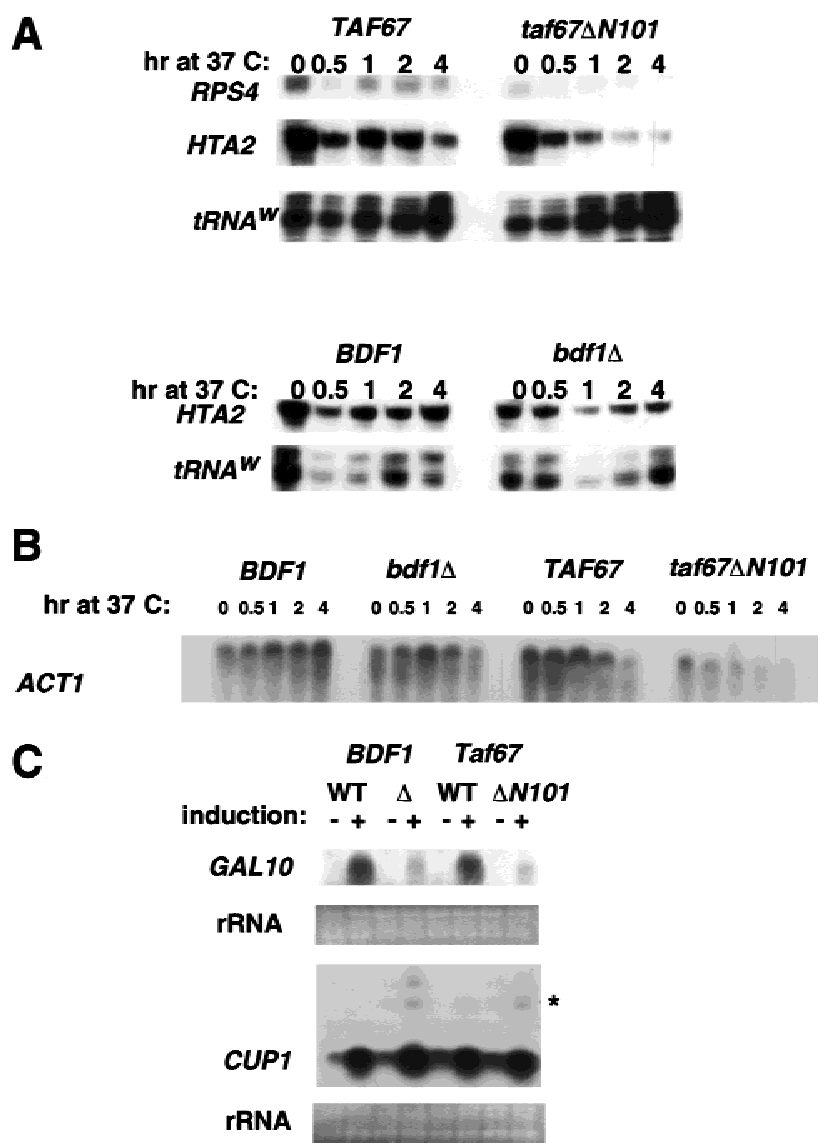

Figure 3. The Bdf-interacting region of Taf67 is important for proper gene expression at several loci. $(A) \mathrm{S} 1$ nuclease protection assay of mRNAs in taf67 $\Delta N 101$ and $b d f 1 \Delta$ strains. RNA was isolated from wild-type or mutant strains incubated at $37^{\circ} \mathrm{C}$ for the indicated amount of time. Probes for RPS4 and HTA2 were used to monitor the levels of those transcripts. A probe for $t R N A^{w}$ was used as an internal control. $(B)$ Northern blot analysis of ACT1 transcript levels. The RNA samples used in $A$ were resolved by agarose gel and blotted to a membrane. ACT1 antisense riboprobe was used to detect the ACT1 mRNA. (C) Both taf67DN101 and bdf1A show a defect in response of GAL10 to induction by galactose, but not CUP1 induction by copper. Northern blot analysis was used to monitor the level GAL10 or CUP1 transcripts after induction as described in Materials and Methods. Radioactively labeled GAL10 or CUP1 antisense riboprobes were used to detect the transcripts after blotting. Anomalous larger CUP1 mRNA species are denoted by an asterisk $\left({ }^{\star}\right)$. Ethidiumbromide staining of rRNA is shown as a control for total RNA. 
netics of reduction were similar to those seen previously with taf40, taf60, and taf61 temperature-sensitive strains (Michel et al. 1998; Komarnitsky et al. 1999). However, levels of total poly $(\mathrm{A})^{+}$mRNA in the taf67 $\Delta$ N101 strain remained high for at least $6 \mathrm{hr}$ after temperature shift, suggesting that this allele did not result in a complete loss of transcription (referred to as taf67-1 in Michel et al. 1998).

In contrast to taf $67 \Delta N 101$, the $b d f 1 \Delta$ strain did not exhibit a decrease in any of the three mRNAs at the nonpermissive temperature. Also, taf67 0 N101 extracts were inactive for in vitro transcription, whereas $b d f 1 \Delta$ extracts had weak activity (data not shown). The $b d f 1 \Delta$ strain still contains wild-type Bdf2, which is likely to be functionally redundant with Bdf1. Therefore, we cannot conclusively determine whether Bdf1 and Bdf2 play a widespread role in Pol II transcription from these experiments. The phenotypes of the BDF1 deletion could be explained by selective transcription defects.

As TAFs have been postulated to have a coactivator function, we tested whether Taf 67 and Bdf1 play a role in gene activation. The inducible genes GAL10 and CUP1 were assayed in $t a f 67 \Delta N 101, b d f 1 \Delta$, and the corresponding isogenic wild-type strains. Cells were grown in the presence of galactose for induction of GAL10 or copper for induction of CUP1. Northern blot analysis was used to detect the level of GAL10 and CUP1 messages. Activation of GAL10 is clearly defective in both taf67 $\Delta$ N101 and $b d f 1 \Delta$ strains (Fig. 3C), consistent with the $\mathrm{Gal}^{-}$phenotype of both strains. In contrast, activation of CUP1 by copper is normal in both mutant strains. CUP1 induction is also independent of several essential transcription factors such as Kin28, Srb4, the CTD of RNA Pol II largest subunit, and Taf17 (Lee and Lis 1998; McNeil et al. 1998; Moqtaderi et al. 1998) and may be atypical of most genes.

Interestingly, a larger CUP1 mRNA species is ob-

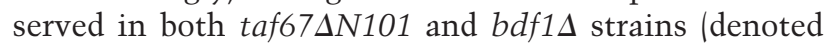
with asterisk in Fig. 3C). A similar mRNA was observed previously during CUP1 transcription by a CTD-truncated Pol II, apparently resulting from transcription past the normal poly(A) site (McNeil et al. 1998). The CTD of Pol II has been shown to play a crucial role in linking transcription to RNA processing. Perhaps related to this coupling, TFIID has been suggested to recruit CPSF (cleavage and polyadenylation specificity factor) to the initiation complex. The human homolog of Taf67, hTAF $_{\mathrm{II}} 55$, participates in the interaction between CPSF and the TAF complex (Dantonel et al. 1997). Further studies will be required to determine whether Taf67 and Bdf1 play a role in an interaction with polyadenylation machinery.

To further explore defects in gene expression in taf67 $\Delta N 101$ and $b d f 1 \Delta$ strains, a $\beta$-galactosidase assay was utilized to measure levels of activation from $1 a c Z$ reporter constructs under the regulation of a GALUAS or the FUS1 promoter. Yeast cells harboring the reporter constructs were induced with galactose $(G A L)$ or $\alpha$-factor (FUS1). Wild-type strains showed increasing expression of lacZ over time after induction with galactose, but both taf67 $\Delta N 101$ and $b d f 1 \Delta$ strains showed only very low levels of $1 a c Z$ expression (data not shown). Similarly, in yeast strains expressing lac $Z$ under the regulation of the FUS1 promoter, both parent strains expressed increasing amounts of lac $Z$ in response to $\alpha$-factor,

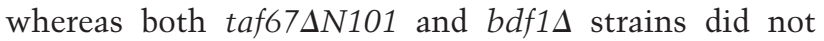
show any induction at all (data not shown). Other reporter constructs also exhibited unusual responses, although in some cases there appeared to be higher levels of transcription in the mutant strains than in the wildtype isogenic strain (data not shown). These results support the physiological significance of the interaction between Bdf1 and Taf67 observed in the yeast two-hybrid assay. Bdf1 and the amino terminus of Taf 67 appear to be important for the proper regulation of several genes. Future analysis of genome-wide expression arrays should show whether there are genes that specifically depend on Bdf1 or Bdf2.

The carboxy-terminal region of Bdf1 interacts with TFIID

To determine whether Bdf1 interacts with Taf67 in the context of the TFIID complex, a protein interaction assay was used. Glutathione $S$-transferase (GST) was fused to the first 30 amino acids and the carboxy-terminal 266 amino acids of Bdf1 to produce GST-Bdf1(C) (Chua and Roeder 1995). Glutathione agarose beads carrying GSTBdf1(C) or GST alone were incubated with whole cell extracts from a yeast strain carrying epitope-tagged Taf67 (Taf67HA) or an untagged wild-type strain. Bound proteins were analyzed by SDS-PAGE and immunoblotting (Fig. 4). GST-Bdf1(C) retains Taf67 as well as Taf145, Taf61, and Taf60; the GST beads did not. This result supports the hypothesis that Bdf1 interacts with TFIID via its carboxyl terminus.

We used coimmunoprecipitation to test whether endogenous Bdf1 is associated with TFIID in yeast extracts. Whole cell extract containing epitope-tagged Taf67HA was immunoprecipitated with $\alpha$-HA monoclonal antibody (12CA5) or $\alpha$-Bdf1 antibody. Pellets were analyzed by SDS-PAGE and immunoblotting (Fig. 5A). $\alpha$-HA antibody coimmunoprecipitates Bdf1 in Taf67HA extract (Fig. 5A, lane 6), but not in untagged wild-type extract (Fig. 5A, lane 5). In the reciprocal reaction, $\alpha$-Bdf1 antibody immunoprecipitates Taf67HA (Fig. 5A, lane 8). Preimmune serum failed to precipitate either factor. It was noted that detection of Bdf1 coprecipitated with Taf67HA required a longer exposure time than in other panels. Also, the amount of Taf67HA coprecipitated with $\alpha$-Bdf1 pellets was much lower than that precipitated with $\alpha$-HA antibody. These results indicate that Bdf1 interacts with Taf67, but that the association could be weak or substoichiometric under these experimental conditions.

Whole-cell extracts from a wild-type or $b d f 1 \Delta$ strain were subjected to immunoprecipitation with $\alpha$-TBP or $\alpha$-Bdf1 antibody to determine whether native Bdf1 associates with TFIID as a complex (Fig. 5B). As shown in lane 5, $\alpha$-TBP antibody coprecipitates several TAFs as 


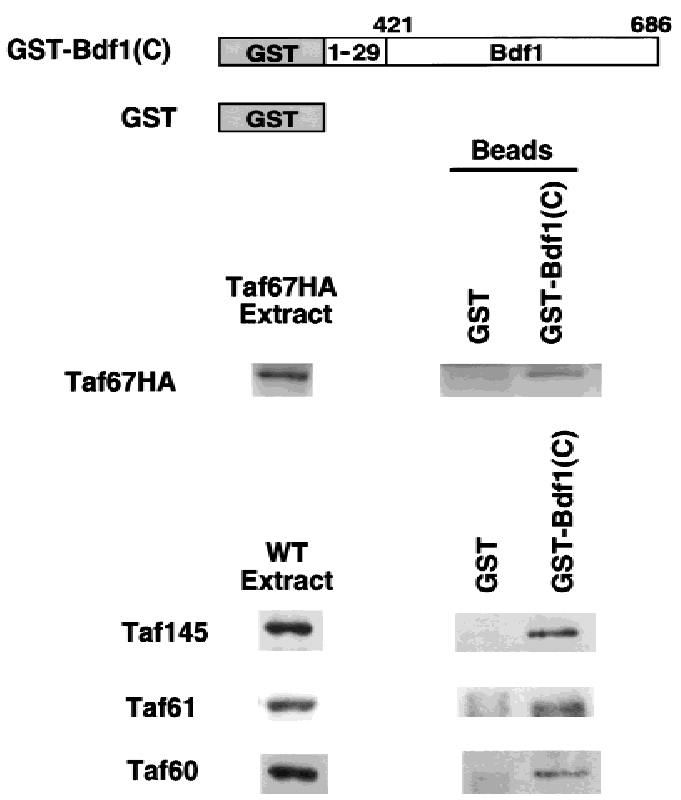

Figure 4. The carboxyl terminus of Bdf1 interacts with TFIID in vitro. Recombinant GST or GST-Bdf1(C) proteins were bound to glutathione agarose beads and incubated with whole cell extracts from a strain containing the HA epitope-tagged Taf67 (Taf67HA, YSB458) or a wild-type strain (YSB382). After being washed extensively, the precipitates were resolved by SDS-PAGE, blotted, and probed with indicated antibodies. The first lane shows the signal in total extracts, whereas the second and third show the proteins precipitated with GST or GSTBdf1(C), respectively.

well as Bdf1. Again, detection of Bdf1 required longer exposure time than other TAFs. Immunoprecipitation with $\alpha$-Bdf1 antibody also precipitates several TAF subunits (lane 7). Importantly, $\alpha$-Bdf1 antibody did not precipitate any TAFs in a $b d f 1 \Delta$ extract (lane 8 ). Addition of the recombinant GST-Bdf1(C) protein to the $b d f 1 \Delta$ extract (lane 9) restored the ability to precipitate TFIID subunits with $\alpha$-Bdf1 antibody. Interestingly, very little TBP was coprecipitated with Bdf1. This recalls our earlier observation that immunoprecipitates done with epitope-tagged Taf67 contained much less TBP than precipitations of extracts containing other tagged TAFs (Moqtaderi et al. 1996a). Therefore, Taf67 and Bdf1 may both be less tightly associated with TFIID complex containing TBP.

Our results indicate that Bdf1 is at least partly associated with the TFIID complex in vivo and that Bdf1 satisfies the operational definition of a TAF, that is, association with TBP. Significantly, $\alpha$-Bdf1 precipitates did not contain detectable levels of the SAGA complex components Gen5 or Ada3 (data not shown). Therefore, unlike a subset of TAFs, Bdf1 appears to be specifically associated with TFIID.

$B d f 1$ is recruited to the promoter with the transcription preinitiation complex

If Bdf1 is associated with TFIID and functions in RNA
Pol II transcription, it might be recruited to the promoter as part of the transcription preinitiation complex (PIC). To test this hypothesis, we used an immobilized template assay (Cho and Buratowski 1999) in which PICs are assembled on DNA templates coupled to beads. Whole cell extract was incubated with the beads in the presence of the activator Gal4-VP16. To determine DNA sequence specificity, three different templates were used, one with the CYC1 basal promoter region and a Gal4binding site, one with a Gal4-binding site but no promoter, and one without any promoter or Gal4-binding site. All three templates contained an identical G-less cassette. Proteins bound to the beads were subjected to SDS-PAGE and immunoblot analysis (Fig. 6). Two basal transcription factors [the large subunit of TFIIE (Tfa1) and TBP] were used as markers for promoter-dependent PIC assembly. Both proteins were bound only in the presence of a functional promoter. Significantly, Bdf1 also associated only with a promoter-containing template. Similar levels of Bdf1 were also recruited to the promoter in the absence of a Gal4-binding site (data not

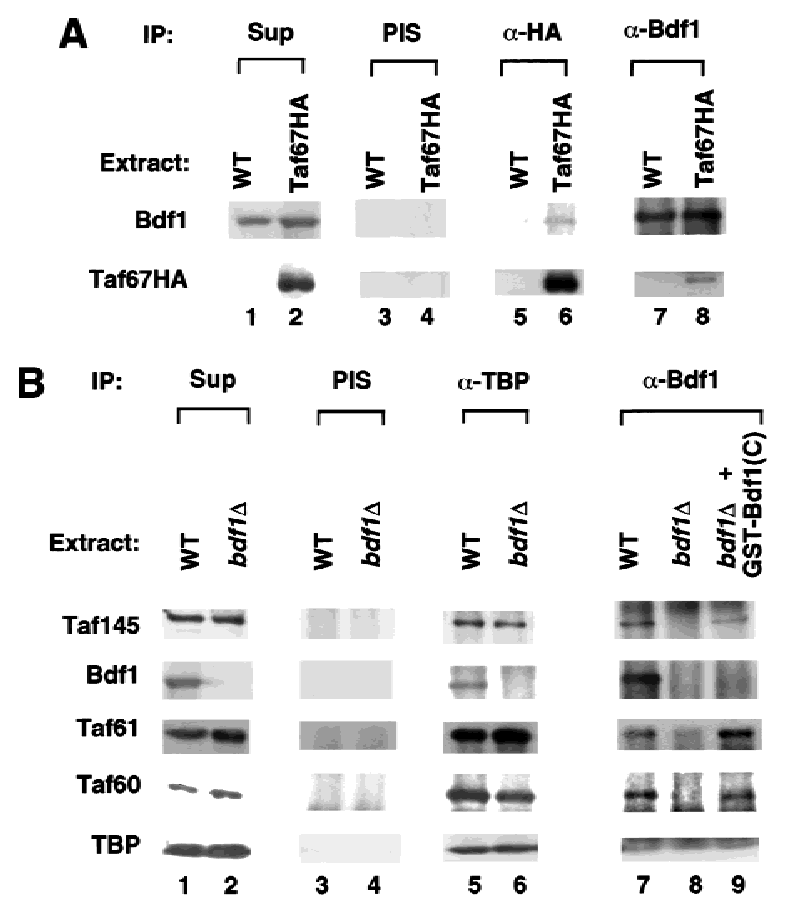

Figure 5. Bdf1 coimmunoprecipitates with TFIID components. (A) Bdf1 coimmunoprecipitates with Taf67. Extract (Taf67HA) from strain YSB458 carrying an epitope-tagged Taf67 was immunoprecipitated (IP) with preimmune serum (PIS), mAb 12CA5 ( $\alpha$-HA), or $\alpha$-Bdf1 polyclonal antibody as indicated. The signal in total extract (Sup) is also shown. Wild-type (WT) extract serves as a negative control for the epitope tag. $(B)$ Bdf1 coimmunoprecipitates with TFIID components. Extracts from a wild-type (WT, YSB382) or bdf1s strain (YSB496) were immunoprecipitated with preimmune serum (PIS), $\alpha$-TBP antibody, or $\alpha$-Bdf1 antibody as indicated. $b d f 1 \Delta$ plus GST-Bdf1(C) is $b d f 1 \Delta$ extract with $125 \mathrm{ng}$ of recombinant GST-BDF1(C) protein added before immunoprecipitation. The precipitates were resolved on SDS-PAGE, blotted, and probed with indicated antibodies. 


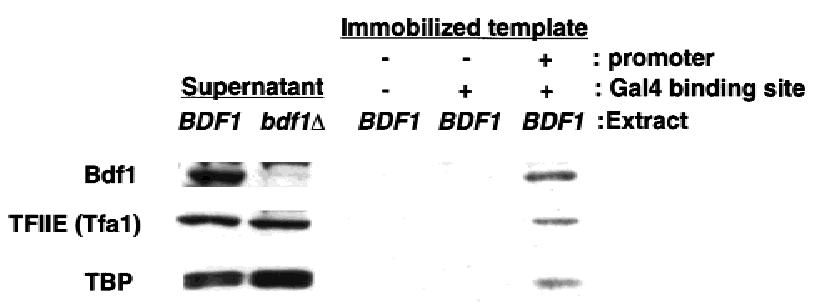

Figure 6. Bdf1 is recruited to a promoter. Extract from a wildtype (BDF1, YSB382) strain was incubated with three immobilized template DNAs carrying the indicated promoter elements. Transcription complexes were assembled on beads in the presence of Gal4-VP16 activator. After extensive washing, beads were immunoblotted to test for the presence of Bdf1, the large subunit of TFIIE (Tfal), and TBP. Extract from a $b d f 1 \Delta$ strain (YSB496) was loaded as a control for $\alpha$-Bdflantibody specificity. Basal promoter sequences were necessary for binding of all three factors. In experiments not shown, it was found that the Gal4binding site was not required and only modestly stimulated association of the three factors.

shown), indicating that the activator is not required for promoter association. Therefore, Bdf1 is associated with a promoter in a manner similar to TBP and other general transcription factors, consistent with a role in RNA Pol II transcription.

\section{Bdf1 has an associated kinase activity}

The domain structure of Bdf1 (two bromodomains followed by an acidic region) is similar to a family of proteins that include Drosophila female sterile homeotic and the mammalian RING3 protein. Furthermore, the largest TFIID subunit from higher eukaryotes (TAF $\left.{ }_{\mathrm{II}} 250\right)$ also contains two bromodomains and acidic region. Taf145, the yeast homolog of $\mathrm{TAF}_{\mathrm{II}} 250$, aligns with only the amino-terminal half of $\mathrm{TAF}_{\mathrm{II}} 250$ and does not contain the bromodomains found in the carboxy-terminal half of $\mathrm{TAF}_{\mathrm{II}} 250$. This raises the possibility that within yeast TFIID, Bdf1 and/or Bdf 2 corresponds to the missing part of $\mathrm{TAF}_{\mathrm{II}} 250$.

An autophosphorylating kinase activity has been mapped to the carboxy-terminal region of $\mathrm{TAF}_{\mathrm{II}} 250$ (Dikstein et al. 1996). The human RING3 protein also exhibits autophosphorylation activity (Denis and Green 1996). To investigate whether Bdf1 has a similar activity, $\alpha$-Bdf1 immunoprecipitates were incubated in phosphorylation buffer containing $\left[\gamma^{-32} \mathrm{P}\right]$ ATP. Phosphorylated proteins were visualized by gel electrophoresis, blotting to a membrane, and autoradiography. $\alpha$-Bdf $1 \mathrm{im}$ munoprecipitates from a wild-type extract contain two major phosphorylated proteins (Fig. 7A, lane 3) that are not seen in a $b d f 1 \Delta$ extract (lane 5 ). The slower migrating protein (open arrow) corresponds to Bdf1, which runs in SDS-PAGE at $94 \mathrm{kD}$ (Lygerou et al. 1994). A second phosphorylated protein was observed at $43 \mathrm{kD}$ and represents a potential substrate for the Bdf1 kinase activity. Addition of recombinant GST-Bdf1(C) protein to whole cell extract prior to the immunoprecipitation (Fig. 7A, lanes
4 and 6) resulted in phosphorylation of the fusion protein (closed arrow), indicating that at least one phosphorylation site lies in the carboxyl terminus of Bdf1. Furthermore, recombinant GST-Bdf1(C) added to a $b d f 1 \Delta$ extract was still phosphorylated and restored coprecipitation of the $43-\mathrm{kD}$ protein, indicating that kinase activity and binding to the $43-\mathrm{kD}$ protein are associated with the carboxy-terminal region of Bdf1. We also found phosphorylation of Bdf2 in immunoprecipitates from yeast extract, although the $43-\mathrm{kD}$ band was not apparent $(\mathrm{O}$. Matangkasombut, unpubl.).

Bdfl could either have intrinsic kinase activity or be associated with a kinase found in yeast extracts. Bacterially produced full-length Bdf1 and GST-Bdf1(C) apparently autophosphorylate in vitro in the absence of any additional eukaryotic factors (Fig. 7B). This result suggests that Bdf1 possesses intrinsic kinase activity and that this activity is localized to the carboxyl terminus, as reported previously for $\mathrm{TAF}_{\mathrm{II}} 250$ and RING3 (Denis and Green 1996; Dikstein et al. 1996). However, autophosphorylation activity appeared weaker than that

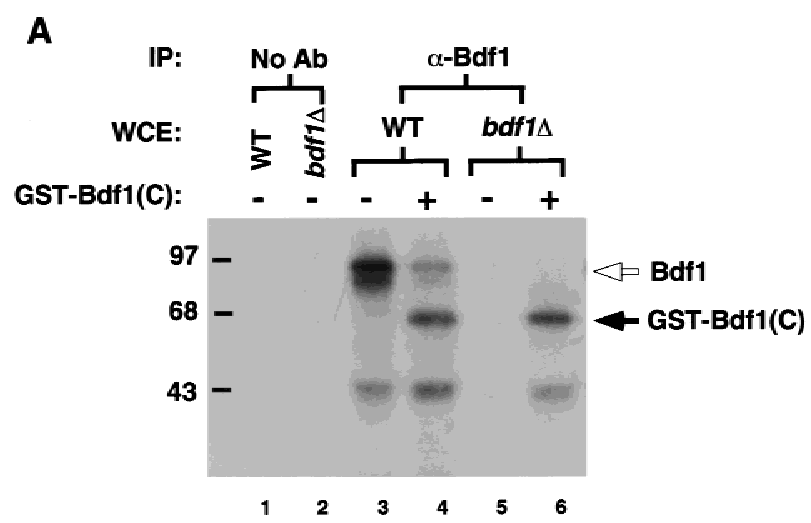

B

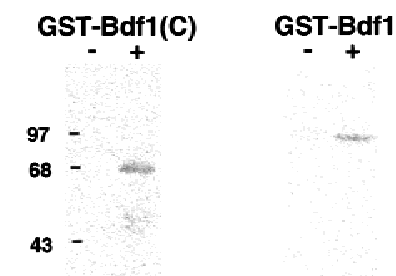

Figure 7. Bdf1 has an associated kinase activity and is phosphorylated in the carboxy-terminal region. (A) Extract from wild-type (WT, YSB382) and bdf1s (YSB496) strains were immunoprecipitated with $\alpha$-Bdfl antibody or beads alone as a negative control (No Ab). In lanes 4 and 6, recombinant GSTBdf1(C) was added to the wild-type and $b d f 1 \Delta \mathrm{WCE}$, respectively, before immunoprecipitation. Pellets were washed extensively before incubation with phosphorylation buffer containing $\left[\gamma^{-32} \mathrm{P}\right]$ ATP. Phosphorylated proteins were resolved by SDS-PAGE and visualized by autoradiography. (Open arrow) Native Bdf1; (solid arrow) recombinant GST-Bdf1(C). (B) GST fused to full-length Bdf1 or Bdf1(C) were produced in bacteria, purified by glutathione-agarose affinity chromatography, and tested in a kinase assay as in $A$ except that phosphorylated proteins were visualized by PhosphorImager. 
Matangkasombut et al.

observed in yeast extracts, suggesting that other proteins or modifications may stimulate Bdf1 kinase activity. To completely rule out the possibility that Bdf1 is phosphorylated by other associated kinases, it will be necessary to identify Bdf1 mutants without kinase activity.

\section{Discussion}

Using a yeast two-hybrid screen, we discovered that Bdf1 and its homolog Bdf2 interact with the Taf67 TFIID subunit. Genetic and biochemical evidence support the physiological relevance of this interaction. Deletion of $B D F 1$ or a truncation of the Taf67 Bdf-interacting domain (taf67 $\Delta$ N101) results in several phenotypes including temperature sensitivity, flocculence, and selective defects in transcription. Bdf1 associates with TFIID and is recruited to a promoter with components of the transcription preinitiation complex. Thus, Bdf1 behaves like a TAF both in vitro and in vivo. Its domain structure and functional characteristics suggest that Bdf1 might correspond to the carboxy-terminal half of higher eukaryotic TAF $_{\mathrm{II}} 250$ (Fig. 8A).

As TFIID is a key component of the RNA Pol II transcription machinery, disruption of the Taf67/Bdf inter- action might be expected to affect gene expression. At $30^{\circ} \mathrm{C}$, neither a taf67 $\Delta N 101$ nor bdf1 $\Delta$ strain induce GAL10 transcription in the presence of galactose or a FUS1 reporter gene in the presence of $\alpha$-factor. Upon shifting the temperature-sensitive taf67 $\Delta$ N101 strain to the nonpermissive temperature, additional transcription defects are observed including a loss of ACT1, RPS4, and HTA2 transcription. However, total poly $(\mathrm{A})^{+}$mRNA levels do not dramatically decrease (Michel et al. 1998; data not shown). Recently, the Schizosaccharomyces pombe homolog of Taf67, ptr6 ${ }^{+}$[poly(A) ${ }^{+}$RNA transport] was the implicated nucleocytoplasmic transport of mRNA (Shibuya et al. 1999). A temperature-sensitive ptr6 mutant strain shows a widespread defect in Pol II transcription after shifting to nonpermissive temperature and this may indirectly contribute to the transport defect. The difference between the specific gene expression defects seen with our taf67 $\Delta$ N101 strain and the general defect with the ptr6 mutant could reflect different roles of the Taf in the two species. We suspect that it is more likely due to differences in allele severity because the taf67 $\Delta$ N101 strain does not show the rapid cessation of growth and loss of viability that correlates with loss of transcription in our other Taf mutants (Michel et al. 1998; Komarnitsky et al. 1999).

A
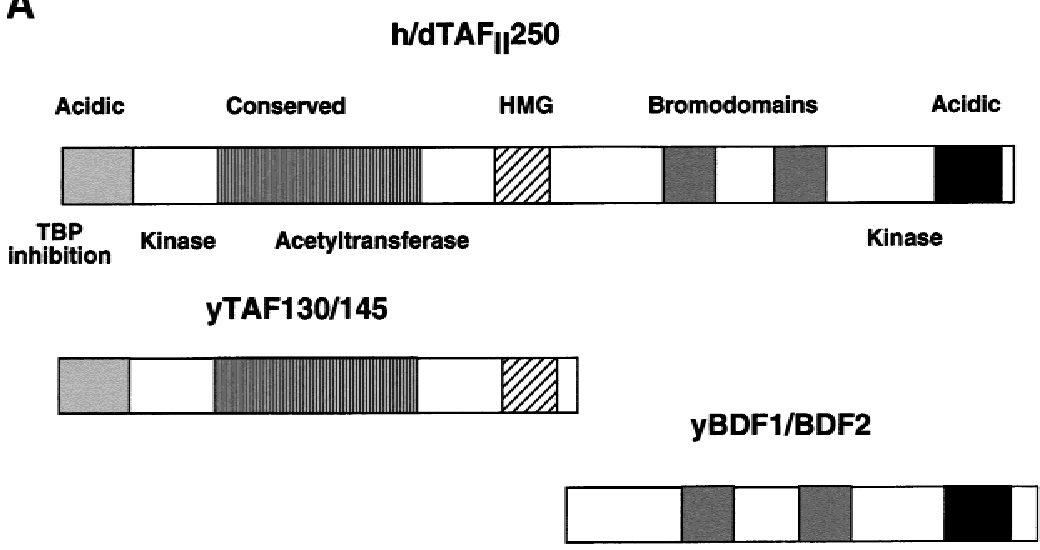

B

Figure 8. Bdf1 corresponds to the carboxy-terminal region of $\mathrm{TAF}_{\mathrm{II}} 250$. (A) Schematic alignment of Taf145/Bdf1 and $\mathrm{TAF}_{\mathrm{II}} 250$. (B) Speculative model for Bdf1 function. The activator (Act) can recruit a HAT such as SAGA to locally modify nucleosomes (gray circles). The acetylated histone tails (Ac) might bind Bdf1 (or the bromodomains of $\mathrm{TAF}_{\mathrm{II}} 250$ in higher eukaryotes). This would in turn localize TFIID near the promoter to increase occupancy and transcription. Note that the binding of Bdf1 to acetylated nucleosomes could precede TFIID recruitment or occur simultaneously as a cooperative binding event. Because several HAT complexes contain TAFs, the identical activator-TAF interaction could mediate both HAT as well as TFIID stabilization at the promoter.

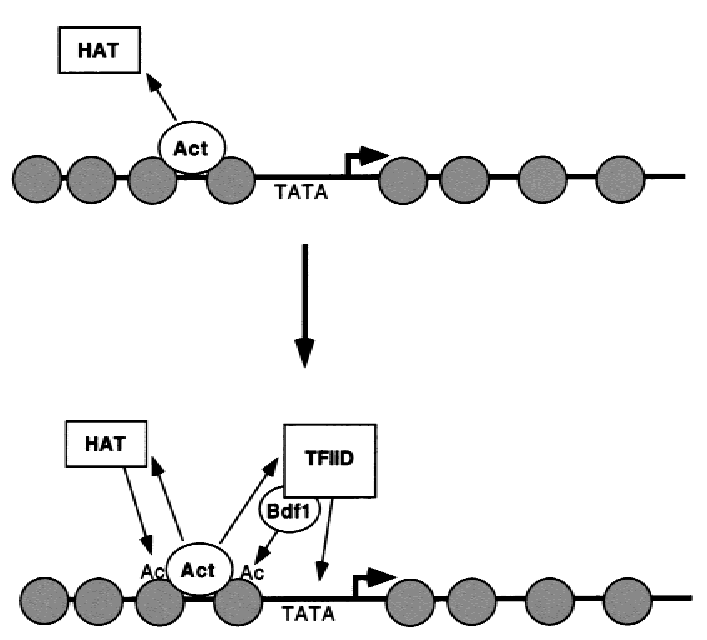


The $b d f 1 \Delta$ strain also does not show reduced levels of poly $(\mathrm{A})^{+}$RNA at the nonpermissive temperature. Furthermore, it has only a subset of the gene expression defects seen with taf67 $\Delta$ N101. This may be because Bdf2 can function in place of Bdf1. This idea is supported by the findings that the double deletion of $B D F 1$ and $B D F 2$ is inviable and that overexpression of $B D F 2$ suppresses the temperature sensitivity of $b d f 1 \Delta$. If either Bdf1 or Bdf 2 can function in association with Taf67, there may be two functionally distinct forms of TFIID within yeast cells. It is clear that Bdf1 and Bdf2 are not completely redundant as bdf1 $\Delta$ shows more severe phenotypes than $b d f 2 \Delta$. Therefore, there may be promoters that function specifically with only Bdf1- or Bdf2-associated TFIID. Alternatively, Bdf1 could be the major bromodomain factor, whereas Bdf2 is normally used only under certain growth conditions.

The Bdf proteins contain two bromodomains and an acidic carboxyl terminus. It is intriguing that these same features are seen in $\mathrm{TAF}_{\mathrm{II}} 250$ from higher eukaryotes, but are missing in its yeast homolog Taf145. The $\mathrm{TAF}_{\mathrm{II}} 250$ carboxy-terminal region and RING3 exhibit autophosphorylation activity (Denis and Green 1996; Dikstein et al. 1996) and we observe a similar activity in the carboxy-terminal region of Bdf1. Neither $\mathrm{TAF}_{\text {II }} 250$, Bdf1, or RING3 closely resemble known kinases and may therefore represent a new kinase family. It will be interesting to determine the functional role of autophosphorylation, as well as the identities of any heterologous substrates.

Intriguingly, the bromodomain is found almost exclusively in proteins involved in transcription and chromatin structure such as nuclear histone acetyltransferases (HATs) and chromatin remodeling factors (Jeanmougin et al. 1997). The importance of the bromodomain varies in different proteins (for review, see Winston and Allis 1999|. The Gcn5 bromodomain specifically stimulates acetylation of nucleosomes relative to free histones by the SAGA complex (Sterner et al.1999) and can interact with histone $\mathrm{H} 3$ and $\mathrm{H} 4$ amino-terminal tails /Ornaghi et al. 1999). The P/CAF bromodomain interacts specifically with an acetyl-lysine analog (Dhalluin et al. 1999). On the basis of these findings, it has been proposed that bromodomains function to target their respective protein complexes to acetylated nucleosomes (Dhalluin et al. 1999; Winston and Allis 1999). Because several HAT complexes themselves contain bromodomains, this could be an important feedback mechanism for maintaining the acetylated state of a nucleosome.

How does nucleosome acetylation lead to increased transcription? One model postulates that promoters within acetylated nucleosomes are simply more accessible to regulatory and basal transcription factors because of a less compact chromatin structure. Our results raise the possibility of a more direct mechanism (Fig. 8B). Transcription activators could recruit one or more HAT complexes to a promoter, resulting in localized nucleosome acetylation (Natarajan et al. 1998; Cosma et al. 1999). Mediated by the two bromodomains of the Bdf proteins (or $\mathrm{TAF}_{\mathrm{II}} 250$ in higher eukaryotes), TFIID could be localized to these acetylated nucleosomes and preferentially delivered to nearby promoters. This is consistent with the gene expression defects observed in the Bdf1 and Taf67 mutants. It also explains the dominantnegative effects seen upon overexpression of full-length or truncated Bdf1 derivatives (Chua and Roeder 1995; this work): These might bind acetylated nucleosomes and block TFIID recruitment.

Several other proteins show a domain arrangement similar to Bdf1 and Bdf2, including the mammalian RING3 and the Drosophila female sterile homeotic proteins. One might predict that these proteins serve to recruit Pol II or other cellular machineries to acetylated nucleosomes. Consistent with this proposal, a mouse RING3 protein has been found associated with a mammalian mediator complex (Jiang et al. 1998). The twobromodomain-acidic kinase domain arrangement may be a functional module that has been permanently incorporated into $\mathrm{TAF}_{\mathrm{II}} 250$ during evolution of higher eukaryotes. It will be interesting to see whether similar modules act in transcription by the RNA Pol I and Pol III systems or in other processes such as replication and DNA repair.

\section{Materials and methods}

\section{RNA analysis}

Yeast cells were grown to early log phase at room temperature and then shifted to the nonpermissive temperature of $37^{\circ} \mathrm{C}$. At the indicated times, cells were harvested and washed once with cold water. For GAL10 induction, cells were grown in selective medium containing $2 \%$ raffinose to early log phase and divided in half. The medium was changed to $2 \%$ galactose for induction of GAL10 in one-half and kept at $2 \%$ raffinose in the other half as a negative control. For CUP1 induction, cells were grown to early log phase in the absence of copper and divided in half. Copper sulfate $\left(\mathrm{CuSO}_{4}\right)$ was added to $1 \mathrm{~mm}$ final concentration in the induced culture. Samples were collected after $1 \mathrm{hr}$ of induction for GAL10 and $30 \mathrm{~min}$ for CUP1. RNA was isolated by hot acid phenol extraction (Ausubel et al. 1991) and concentration was determined by measuring the absorbance $\left(A_{260}\right)$.

$\mathrm{S} 1$ nuclease protection assays were performed as described (Michel et al. 1998; Komarnitsky et al. 1999). Northern blot analysis was performed as described (Ausubel et al. 1991). RNA (20 $\mathrm{\mu g} /$ lane) was electrophoresed on $1 \%$ agarose formaldehyde gels and transferred to GeneScreen (DuPont). Transcripts were detected by hybridizing with radioactively labeled antisense riboprobes that were generated as described (Fresco and Buratowski 1996).

\section{Yeast methods}

Yeast strains used in this study are listed in Table 1. Reporter constructs used were pLGSD5 containing the GAL UAS and CYC1 promoter driving lacZ expression (gift of L. Guarente, MIT, Cambridge, MA), and pSB231 containing the FUS1 promoter driving lacZ expression (gift of E. Elion, Harvard Medical School, Boston, MA). Cells were grown to mid-log phase in selective medium and subjected to induction by galactose for pLGSD5 or $\alpha$-factor for pSB231. For pLGSD5, the induction was done by switching the medium to $2 \%$ raffinose plus $2 \%$ galactose and the samples were collected at the indicated time points 
Table 1. Yeast strains used in this study

\begin{tabular}{|c|c|c|}
\hline Strain & Genotype & Source \\
\hline YSB424 & 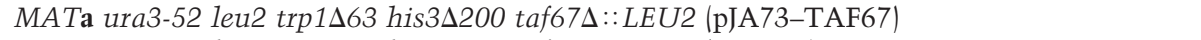 & Moqtaderi et al. (1996) \\
\hline YSB458 & 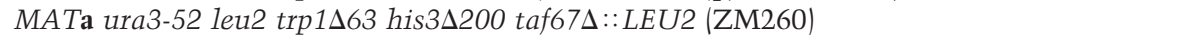 & Moqtaderi et al. (1996) \\
\hline YSB479 & 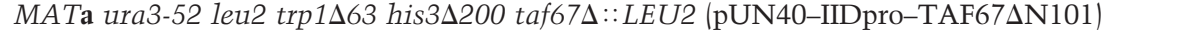 & YSB424 plasmid shuffle \\
\hline YSB634 & 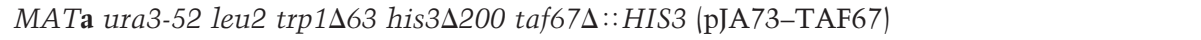 & YSB424 marker switch \\
\hline YSB647 & 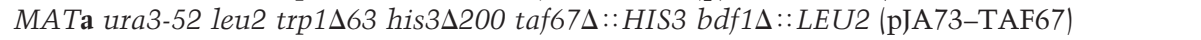 & BDF1 KO of YSB634 \\
\hline YSB496 & 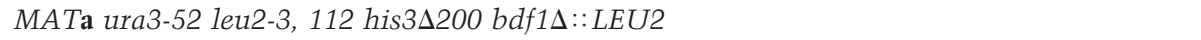 & BDF1 KO of YSB104 \\
\hline YSB497 & 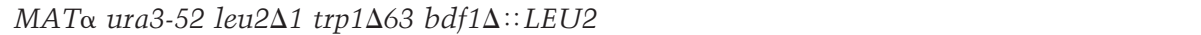 & BDF1 KO of FY24 \\
\hline YSB485 & 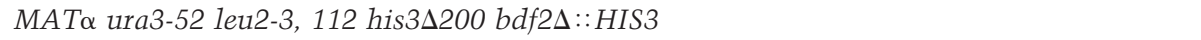 & BDF2 KO of YSB250 \\
\hline YSB520 & 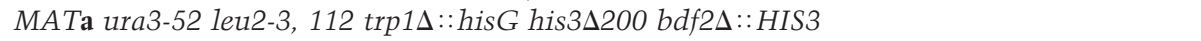 & TRP1 KO of YSB485 \\
\hline YSB525 & 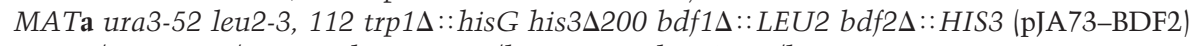 & BDF1 KO of YSB520 \\
\hline YSB490 & 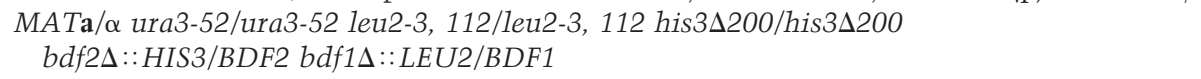 & YSB485 $\times$ YSB496 \\
\hline YSB104 & MATa ura3-52 leu2-3, 112 his3s200 & \\
\hline FY24 & 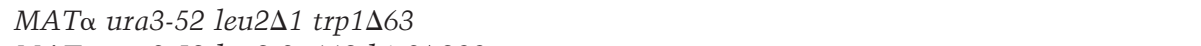 & Fred Winston \\
\hline YSB250 & 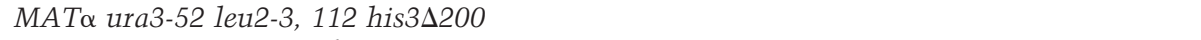 & \\
\hline YSB382 & $\begin{array}{l}\text { MATa ura3-52 trp1D1 ade2 ACE } \rightarrow \text { ROX1 ACE } \rightarrow \text { UBR1 } \\
\quad \text { tfa1::ANB1 } \rightarrow \text { ROX1UBR/lacl/flu/TFA1; URA3 }\end{array}$ & $\begin{array}{l}\text { Kuldell and Buratowski } \\
\text { (1997) }\end{array}$ \\
\hline HF7C & $\begin{array}{l}\text { MATa ura3-52 leu2-3, } 112 \text { trp1-901 his3D200 ade2-101 lys2-801 gal4-542 gal80-538 } \\
\text { LYS2::GAL1UAS-GAL1TATA-HIS3 URA3::GAL417mer(×3)-CYC1TATA-lacZ }\end{array}$ & Feilotter et al. (1994) \\
\hline Y153 & 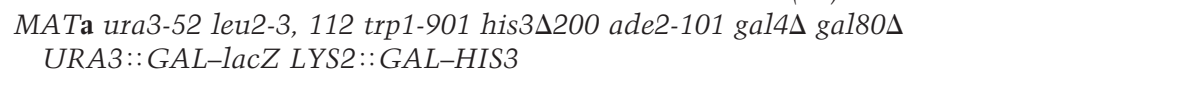 & Durfee et al. (1993) \\
\hline
\end{tabular}

after induction. For pSB231, $\alpha$-factor was added to a final concentration of $5 \mu \mathrm{M}$ and cells were harvested after $2 \mathrm{hr}$ of induction. $\beta$-galactosidase assays were performed as described (Ausubel et al. 1991).

The effect of deleting both Bdf1 and Bdf2 was tested by crossing YSB496 and YSB485 to generate YSB490, followed by sporulation. Also, the double deletion strain YSB525 was constructed by sequentially transforming YSB520 with pJA73-BDF2 and the Bdf1 deletion construct pCB74 (Chua and Roeder 1995). YSB525 was used for complementation testing of Bdf1 deletion derivatives by plasmid shuffling (Fig. 2). Yeast two-hybrid experiments were carried out as described in Durfee et al. (1993) (strain Y153) and Feilotter et al. (1994) (strain HF7c) using the GAL-HIS3 reporter. Plasmid constructs encoding Gal4 fusions were made in vectors from Durfee et al. (1993) and Sadowski et al. (1994). Details of plasmid construction will be provided upon request.

\section{Protein preparation}

Yeast whole cell extracts were prepared as in Woontner et al. (1991) with minor modifications.

Recombinant GST-Bdf1 and GST-Bdf1(C) were expressed from plasmids pGEX-1-BDF1 and pCB152, respectively (provided by G.S. Roeder; see Chua and Roeder 1995), in Escherichia coli BL21. The GST-Bdf1(C) fusion protein contains the first 30 amino acids and the last 236 amino acids of Bdf1 fused to glutathione $S$-transferase. Cells were grown to $\mathrm{OD}_{600}$ of 0.6 at $37^{\circ} \mathrm{C}$, induced with $0.1 \mathrm{~mm}$ of IPTG, and further grown at room temperature overnight. Cells were lysed in PBS with $0.1 \%$ Triton X-100 and cleared lysate was incubated with glutathione agarose beads (Sigma) at $4^{\circ} \mathrm{C}$ overnight on a rotator. The beads were washed extensively with the same buffer and bound proteins were eluted with $50 \mathrm{~mm}$ Tris buffer at $\mathrm{pH} 8.0$ containing 5 $\mathrm{mM}$ reduced glutathione (Sigma). Eluted fractions were dialyzed against GST-binding buffer $(50 \mathrm{~mm}$ HEPES at $\mathrm{pH}$ 7.5, $100 \mathrm{~mm}$ potassium acetate, $20 \mathrm{~mm}$ magnesium acetate, $5 \mathrm{~mm}$ EGTA, 1 IM DTT, $10 \%$ glycerol, amd $0.01 \%$ NP-40 supplemented with 1
mM PMSF, protease inhibitors, and $0.03 \%$ Triton X-100). Protein concentration was determined by Bradford assay.

\section{Protein interaction assay}

Recombinant GST (provided by E. J. Cho, Harvard Medical School) or GST-Bdf1(C) was immobilized on glutathione agarose beads (100 $\mu \mathrm{g}$ protein/100 $\mu$ l bed volume). Whole cell extracts $(200 \mu \mathrm{g})$ were precleared by incubation with $10 \mu \mathrm{l}$-bed volume of GST bound agarose beads for $1 \mathrm{hr}$ at $4^{\circ} \mathrm{C}$ in binding reaction adjusted to $200 \mu \mathrm{l}$ with GST-binding buffer (described above). Precleared extracts were then incubated with $20 \mu$ l-bed volume of GST-Bdf1(C) or GST bound beads at $4^{\circ} \mathrm{C}$ overnight on a rotator. The beads were washed five times with $200 \mu \mathrm{l}$ of GST-binding buffer and bound proteins were resolved by SDSPAGE. Proteins were detected by immunoblotting.

\section{Immunoprecipitations and immunoblotting}

Immunoprecipitations were performed as described (Moqtaderi et al. 1996a) with some modifications. Briefly, whole cell extracts $(500 \mu \mathrm{g})$ were precleared by incubation for $1 \mathrm{hr}$ at $4^{\circ} \mathrm{C}$ with $50 \mu \mathrm{l}$ of $10 \%$ protein A-Sepharose beads in binding reaction adjusted to $500 \mu \mathrm{l}$ with buffer A. Precleared extracts were then incubated with $50 \mu \mathrm{l}$ of $10 \%$ protein A-Sepharose beads plus $1 \mu \mathrm{l}$ of rabbit preimmune serum, $\alpha$-TBP antibody, or $\alpha$-Bdf 1 antibody (generously provided by G.S. Roeder, Yale University, New Haven, CT) overnight at $4^{\circ} \mathrm{C}$ on a rotator. The beads were washed five times with $800 \mu \mathrm{l}$ of buffer A and subjected to SDS-PAGE analysis. Standard immunoblotting techniques were used to detect proteins present in the immunoprecipitates.

\section{Immobilized template assay}

Immobilized template assays were done as described in Cho and Buratowski (1999) with some modifications. DNA templates for immobilized template assay were generated by PCR with Vent DNA polymerase using a 5'-biotinylated primer Biotin 60 (AC- 
GGTCACAGCTTGTCTGTAAGC), and Reverse primer. PCR products from pGAL4CG-, p1xGAL4G-, and $\mathrm{p}\left(\mathrm{C}_{2} \mathrm{AT}\right)_{19}$ were subjected to agarose gel electrophoresis and electroeluted from gel slices. These templates all contain an identical 400-nucleotide G-less cassette (Cho and Buratowski 1999). The pGAL4CGcontains one Gal4-binding site and the CYC1 basal promoter region, whereas the p1xGAL4G- ${ }^{-}$contains the Gal4-binding site without the basal promoter. Purified DNA fragments were incubated with streptavidin-linked magnetic beads (Dynabeads M280 Streptavidin, Dynal Inc.) overnight at room temperature in buffer I ( $2 \mathrm{M}$ sodium chloride, $10 \mathrm{~mm}$ Tris at $\mathrm{pH} 7.4,0.01 \%$ NP-40). The beads were washed three times with buffer I and three times with TE buffer. Prior to use, the beads were incubated with $0.5 \mathrm{mg} / \mathrm{ml} \mathrm{BSA}$ for $1 \mathrm{hr}$ at room temperature and briefly washed with transcription reaction buffer $(25 \mathrm{~mm}$ HEPES- $\mathrm{KOH}$ at $\mathrm{pH} 7.5,100 \mathrm{~mm}$ potassium acetate, $10 \mathrm{~mm}$ magnesium acetate, $5 \mathrm{~mm}$ EGTA, $2.5 \mathrm{~mm}$ DTT, 10\% glycerol). Whole cell extracts $(100 \mu \mathrm{g})$ were incubated with $3 \mu \mathrm{l}$ of beads in $60 \mu \mathrm{l}$ of transcription reaction buffer for $1 \mathrm{hr}$ to allow the assembly of transcription complexes in the presence of $3 \mu \mathrm{g}$ of $\mathrm{p}\left(\mathrm{C}_{2} \mathrm{AT}\right)_{19}$ as a competitor for nonspecific binding to the G-less cassette. A total of $500 \mathrm{ng}$ of Gal4-VP16 (provided by E.J. Cho, Harvard Medical School, Boston, MA) was also included. The beads were washed extensively with transcription buffer containing $0.003 \%$ NP-40. Bound proteins were resolved by SDSPAGE and analyzed by immunoblotting.

\section{Phosphorylation assay}

Immunoprecipitations were performed as described above. After the beads had been washed extensively, they were resuspended in $15 \mu \mathrm{l}$ of phosphorylation buffer $(20 \mathrm{~mm}$ HEPES-KOH at $\mathrm{pH} 7.5,100 \mathrm{~mm}$ potassium acetate, $7.5 \mathrm{~mm}$ magnesium acetate, $2 \mathrm{~mm} \mathrm{DTT}, 1 \mu \mathrm{M}$ ATP, $2 \%$ glycerol) and $0.3 \mu \mathrm{Ci}$ of $\left[\gamma^{-32} \mathrm{P}\right]$ ATP. Reactions were incubated at room temperature for 1 hr on a rotator and then resolved by SDS-PAGE. Phosphorylated proteins were visualized by autoradiography or PhosphorImager.

\section{Acknowledgments}

We thank P. Chua and G.S. Roeder for providing Bdf1 strains, plasmids, and antibodies. We also thank E. Elion, S. Elledge, W. Forrester, L. Guarente, I. Sadowski, F. Winston, R. Young for providing plasmids; and J. Reese, M. Green, and T. Weil for TAF antibodies. We thank E. J. Cho for her scientific and technical help. This work was supported by NIH grant GM46498. S.B. is Leukemia and Lymphoma Society Scholar. O.M. is supported by the Anandamahidol Foundation under the Royal Patronage of His Majesty the King of Thailand.

The publication costs of this article were defrayed in part by payment of page charges. This article must therefore be hereby marked "advertisement" in accordance with 18 USC section 1734 solely to indicate this fact.

\section{References}

Apone, L.M., C.A. Virbasius, F.C. Holstege, J. Wang, R.A. Young, and M.R. Green. 1998. Broad, but not universal, transcriptional requirement for $\mathrm{yTAF}_{\mathrm{II}} 17$, a histone H3-like TAF $_{\text {II }}$ present in TFIID and SAGA. Mol. Cell 2: 653-661.

Ausubel, F.M., R. Brent, R.E. Kingston, D.D. Moore, J.G. Seidman, J.A. Smith, and K. Struhl. 1991. Current protocols in molecular biology John Wiley and Sons, New York, NY.

Bell, B. and L. Tora. 1999. Regulation of gene expression by multiple forms of TFIID and other novel $\mathrm{TAF}_{\mathrm{II}}$-containing complexes. Exp. Cell Res. 246: 11-19.

Burley, S.K. and R.G. Roeder. 1996. Biochemistry and structural biology of transcription factor IID (TFIID). Annu. Rev. Biochem. 65: 769-799.

Chiang, C.M. and R.G. Roeder. 1995. Cloning of an intrinsic human TFIID subunit that interacts with multiple transcriptional activators. Science 267: 531-536.

Cho, E.J. and S. Buratowski. 1999. Evidence that transcription factor IIB is required for a post-assembly step in transcription initiation. J. Biol. Chem. 274: 25807-25813.

Chua, P. and G.S. Roeder. 1995. Bdf1, a yeast chromosomal protein required for sporulation. Mol. Cell. Biol. 15: 36853696.

Cosma, M.P., T. Tanaka, and K. Nasmyth. 1999. Ordered recruitment of transcription and chromatin remodeling factors to a cell cycle- and developmentally regulated promoter. Cell 97: 299-311.

Dantonel, J.C., K.G. Murthy, J.L. Manley, and L. Tora. 1997. Transcription factor TFIID recruits factor CPSF for formation of 3' end of mRNA. Nature 389: 399-402.

Denis, G.V. and M.R. Green. 1996. A novel, mitogen-activated nuclear kinase is related to a Drosophila developmental regulator. Genes \& Dev. 10: 261-271.

Dhalluin, C., J.E. Carlson, L. Zeng, C. He, A.K. Aggarwal, and M.M. Zhou. 1999. Structure and ligand of a histone acetyltransferase bromodomain. Nature 399: 491-496.

Dikstein, R., S. Ruppert, and R. Tjian. 1996. TAF 250 is a bipartite protein kinase that phosphorylates the base transcription factor RAP74. Cell 84: 781-790.

Durfee, T., K. Becherer, P.L. Chen, S.H. Yeh, Y. Yang, A.E. Kilburn, W.H. Lee, and S.J. Ellendge. 1993. The retinoblastoma protein associates with the protein phosphatase type 1 catalytic subunit. Genes \& Dev. 7: 555-569.

Feilotter, H.E., G.J. Hannon, C.J. Ruddell, and D. Beach. 1994. Construction of an improved host strain for two hybrid screening. Nucleic Acids. Res. 22: 1502-1503.

Fresco, L.D. and S. Buratowski. 1996. Conditional mutants of the yeast mRNA capping enzyme show that the cap enhances, but is not required for, mRNA splicing. RNA 2: 584596.

Grant, P.A., L. Duggan, J. Cote, S.M. Roberts, J.E. Brownell, R. Candau, R. Ohba, H.T. Owen, C.D. Allis, F. Winston et al. 1997. Yeast Gen5 functions in two multisubunit complexes to acetylate nucleosomal histones: Characterization of an Ada complex and the SAGA (Spt/Ada) complex. Genes \& Dev. 11: 1640-1650.

Grant, P.A., D. Schieltz, G.M. Pray, D.J. Steger, J.C. Reese, J.R. Yates, and J.L. Workman. 1998a. A subset of $\mathrm{TAF}_{\mathrm{II}} \mathrm{S}$ are integral components of the SAGA complex required for nucleosome acetylation and transcriptional stimulation. Cell 94: 45-53.

Grant, P.A., D.E. Sterner, L.J. Duggan, J.L. Workman, and S.L. Berger. 1998b. The SAGA unfolds: Convergence of transcription regulators in chromatin-modifying complexes. Trends Cell Biol. 8: 193-197.

Jeanmougin, F., J.M. Wurtz, D.B. Le, P. Chambon, and R. Losson. 1997. The bromodomain revisited. Trends Biochem. Sci. 22: 151-153.

Jiang, Y.W., P. Veschambre, B.H. Erdjument, P. Tempst, J.W. Conaway, R.C. Conaway, and R.D. Kornberg. 1998. Mammalian mediator of transcriptional regulation and its possible role as an end-point of signal transduction pathways. Proc. Natl. Acad. Sci. 95: 8538-8543.

Keaveney, M. and K. Struhl. 1998. Activator-mediated recruitment of the RNA polymerase II machinery is the predomi- 
nant mechanism for transcriptional activation in yeast. Mol. Cell 1: 917-924.

Komarnitsky, P.B., B. Michel, and S. Buratowski. 1999. TFIIDspecific yeast TAF40 is essential for the majority of RNA polymerase II-mediated transcription in vivo. Genes \& Dev. 13: $2484-2489$.

Kuldell, N.H. and S. Buratowski. 1997. Genetic analysis of the large subunit of yeast transcription factor TFIIE reveals two regions with distinct functions. Mol. Cell. Biol. 17: 52885298.

Lavigne, A.C., G. Mengus, M. May, V. Dubrovskaya, L. Tora, P. Chambon, and I. Davidson. 1996. Multiple interactions between $\mathrm{hTAF}_{\mathrm{II}} 55$ and other TFIID subunits. Requirements for the formation of stable ternary complexes between $\mathrm{hTAF}_{\mathrm{II}} 55$ and the TATA-binding protein. J. Biol. Chem. 271: 1977419780.

Lavigne, A.C., G. Mengus, Y.G. Gangloff, J.M. Wurtz, and I. Davidson. 1999. Human $\mathrm{TAF}_{\mathrm{II}} 55$ interacts with the vitamin $\mathrm{D}(3)$ and thyroid hormone receptors and with derivatives of the retinoid $\mathrm{X}$ receptor that have altered transactivation properties. Mol. Cell. Biol. 19: 5486-5494.

Lee, D. and J.T. Lis. 1998. Transcriptional activation independent of TFIIH kinase and the RNA polymerase II mediator in vivo. Nature 393: 389-392.

Lygerou, Z., C. Conesa, P. Lesage, R.N. Swanson, A. Ruet, M. Carlson, A. Sentenac, and B. Seraphin. 1994. The yeast BDF1 gene encodes a transcription factor involved in the expression of a broad class of genes including snRNAs. Nucleic Acids Res. 22: 5332-5340.

McNeil, J.B., H. Agah, and D. Bentley. 1998. Activated transcription independent of the RNA polymerase II holoenzyme in budding yeast. Genes \& Dev. 12: 2510-2521.

Michel, B., P. Komarnitsky, and S. Buratowski. 1998. Histonelike TAFs are essential for transcription in vivo. Mol. Cell 2: 663-673.

Mizzen, C.A., X.J. Yang, T. Kokubo, J.E. Brownell, A.J. Bannister, H.T. Owen, J. Workman, L. Wang, S.L. Berger, T. Kouzarides, et al. 1996. The TAF 250 subunit of TFID has histone acetyltransferase activity. Cell 87: 1261-1270.

Moqtaderi, Z., J.D. Yale, K. Struhl, and S. Buratowski. 1996a. Yeast homologues of higher eukaryotic TFIID subunits. Proc. Natl. Acad. Sci. 93: 14654-14658.

Moqtaderi, Z., Y. Bai, D. Poon, P.A. Weil, and K. Struhl. 1996b. TBP-associated factors are not generally required for transcriptional activation in yeast. Nature 383: 188-191.

Moqtaderi, Z., M. Keaveney, and K. Struhl. 1998. The histone H3-like TAF is broadly required for transcription in yeast. Mol. Cell 2: 675-682.

Natarajan, K., B.M. Jackson, E. Rhee, and A.G. Hinnebusch. 1998. yTAFII61 has a general role in RNA polymerase II transcription and is required by Gen $4 p$ to recruit the SAGA coactivator complex. Mol. Cell 2: 683-692.

Oelgeschlager, T., Y. Tao, Y.K. Kang, and R.G. Roeder. 1998. Transcription activation via enhanced preinitiation complex assembly in a human cell-free system lacking TAFIIs. Mol. Cell 1: 925-931.

Ornaghi, P., P. Ballario, A.M. Lena, A. Gonzalez, and P. Filetici. 1999. The bromodomain of Gen5p interacts in vitro with specific residues in the $\mathrm{N}$ terminus of histone H4. I. Mol. Biol. 287: 1-7.

Sadowski, I., B. Bell, P. Broad, and M. Hollis. 1994. GAL4 fusion vectors for expression yeast or mammalian cells. Gene 118: $137-141$.

Shibuya, T., S. Tsuneyoshi, A.K. Azad, S. Urushiyama, Y. Ohshima, and T. Tani. 1999. Characterization of the ptr6(+) gene in fission yeast: A possible involvement of a transcrip- tional coactivator TAF in nucleocytoplasmic transport of mRNA. Genetics 152: 869-880.

Sterner, D.E., P.A. Grant, S.M. Roberts, L.J. Duggan, R. Belotserkovskaya, L.A. Pacella, F. Winston, J.L. Workman, and S.L. Berger. 1999. Functional organization of the yeast SAGA complex: Distinct components involved in structural integrity, nucleosome acetylation, and TATA-binding protein interaction. Mol. Cell. Biol. 19: 86-98.

Verrijzer, C.P. and R. Tjian. 1996. TAFs mediate transcriptional activation and promoter selectivity. Trends Biochem. Sci. 21: 338-342.

Walker, S.S., J.C. Reese, L.M. Apone, and M.R. Green. 1996. Transcription activation in cells lacking $\mathrm{TAF}_{\mathrm{II}} \mathrm{s}$. Nature 383: $185-188$.

Wang, E.H., S. Zhou, and R. Tjian. 1997. TAF ${ }_{\text {II }}$ 250-dependent transcription of cyclin A is directed by ATF activator proteins. Genes \& Dev. 11: 2658-2669.

Winston, F. and C.D. Allis. 1999. The bromodomain: A chromatin-targeting module? Nat. Struct. Biol. 6: 601-604.

Woontner, M., P.A. Wade, J. Bonner, and J.A. Jaehning. 1991. Transcriptional activation in an improved whole-cell extract from Saccharomyces cerevisiae. Mol. Cell. Biol. 11: 45554560.

Wu, S.Y. and C.M. Chiang. 1998. Properties of PC4 and an RNA polymerase II complex in directing activated and basal transcription in vitro. J. Biol. Chem. 273: 12492-12498.

Wu, S.Y., M.C. Thomas, S.Y. Hou, V. Likhite, and C.M. Chiang. 1999. Isolation of mouse TFIID and functional characterization of TBP and TFIID in mediating estrogen receptor and chromatin transcription. J. Biol. Chem. 274: 23480-23490. 


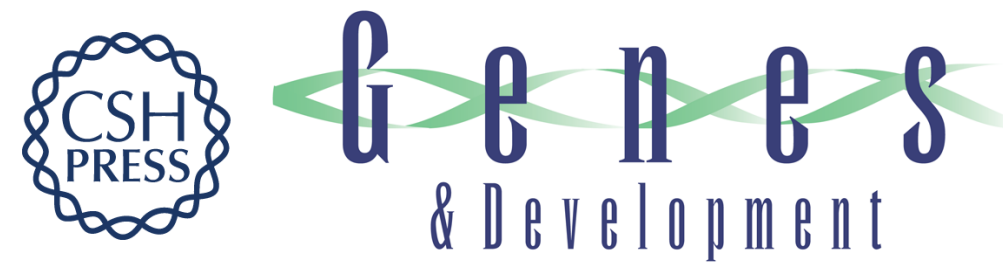

\section{Bromodomain factor 1 corresponds to a missing piece of yeast TFIID}

Oranart Matangkasombut, Robin M. Buratowski, Nathan W. Swilling, et al.

Genes Dev. 2000, 14:

Access the most recent version at doi:10.1101/gad.14.8.951

References This article cites 44 articles, 20 of which can be accessed free at: http://genesdev.cshlp.org/content/14/8/951.full.html\#ref-list-1

License

Email Alerting Receive free email alerts when new articles cite this article - sign up in the box at the top Service right corner of the article or click here.

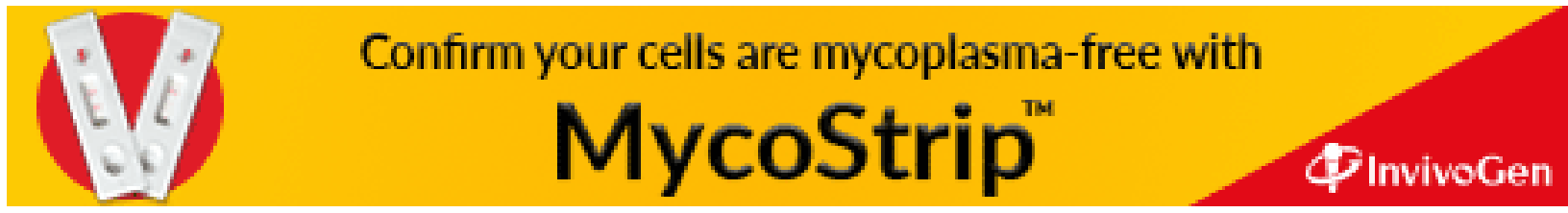

